\title{
Nobreza do sonho, dureza da vida: personagens de Camilo e Manuel Rui às voltas com a aristocracia.
}

\author{
Luiz Maria Veiga $^{1}$
}

RESUMO: Leitura paralela das narrativas "Um parente de cincoenta e três monarcas" do português Camilo Castelo Branco e "Mulato de sangue azul", do angolano Manuel Rui, separadas no tempo mas próximas pela temática: a visão subjetiva dos pretensos herdeiros de linhagens nobres devaneando entre sonhos aristocráticos e entrando em choque com o tratamento que encontram em seu entorno social.

ABSTRACT: Comparative study of two short-stories: "Um parente de cincoenta e três monarcas", by Portuguese writer Camilo Castelo Branco and "Mulato de sangue azul", by Angolan writer Manuel Rui. In spite of being apart in time yet they convey similar themes. They portray the subjective views of two wannabe aristocrats, their delusions of grandeur clashing with the crudities of their social environments.

PALAVRAS-CHAVE: linhagem aristocrática; crise do absolutismo; crise colonial; Camilo, Manuel Rui.

KEYWORDS: aristocratic lineage; crisis of Absolutism; colonial crisis; Camilo; Manuel Rui.

Para a professora doutora Maria Teresa Salgado, por me apresentar Luís Alvim.

O conceito de reificação que foi desenvolvido nestas páginas explica a situação histórica em que a emergência do ego ou do sujeito centrado pode ser entendida: a dissolução dos grupos sociais mais antigos, orgânicos ou hierárquicos, a mercantilização universal da força de trabalho dos indivíduos e seu confronto como unidades equivalentes dentro do quadro do mercado, a anomie desses novos sujeitos individuais "livres" e isolados, com relação à qual só o desenvolvimento protetor de uma couraça monádica surge como uma espécie de compensação.

Fredric Jameson - O inconsciente político

\section{I - Duas palavras sobre duas palavras.}

1 Mestre em Letras e doutorando em Estudos Comparados de Literaturas de Língua Portuguesa (FFLCH/USP) com o projeto "De armas na mão: a representação literária do guerrilheiro em Antonio Callado, Pepetela e Luandino Vieira". Ficcionista e dramaturgo. 
Antes de abordar as narrativas que serão objeto deste estudo, consideramos adequado tecer alguns comentários rápidos, à guisa de introdução, sobre os conceitos de duas palavras que são centrais para entendimento de nosso objeto. As palavras são: aristocracia e nobreza.

Aristocracia, em sua origem grega, tinha o sentido de "governo dos melhores" e era uma das três possibilidades políticas de administração pública (governo de um, ou seja, monarquia; de muitos, ou seja, democracia; e o de poucos, pois era sempre reduzido o número dos melhores que constituíam a aristocracia). Confundindo-se com o poder aristocrático, surge o poder oligárquico, aquela "forma de Governo que será considerada por Aristóteles um desvio da Aristocracia, na medida em que, na oligarquia, os poucos governam no interesse dos ricos e não da comunidade, ao contrário do que acontece na Aristocracia (...)". Originalmente esses melhores que constituíam a Aristocracia atingiam tal condição em decorrência de sua bravura na guerra, ou pela sabedoria e pelo conhecimento, valores não necessariamente transmissíveis por hereditariedade. Para superar este obstáculo logo apareceu uma justificação ideológica:

Mas tanto para Platão como para Aristóteles, todavia - e é uma constante de todo o pensamento político grego -, os aristói, precisamente porque são moral e intelectualmente os melhores, não podem ser senão aqueles que pertencem às classes mais elevadas da sociedade, enquanto agathói, bem nascidos, nobres, e por educação propriamente os bons, contrapostos aos kakói, os mal-nascidos, os maus, a plebe. Em conclusão, podemos ver, sobretudo em Aristóteles, uma oposição entre ricos e pobres: classe aristocrática e classe popular. Assim, o valor ético-pedagógico vem a se identificar com uma precisa situação econômico-social e daqui precisamente podemos passar para outro significado, hoje mais comum, de Aristocracia entendida como grupo privilegiado por direito de sangue (V. NOBREZA). (BOBBIO; MATTEUCCI; PASQUINO, v. I, p. 57, vale para a citação anterior.)

Como a citação acima nos remete ao verbete Nobreza, vejamos algo do que nos diz esse verbete no mesmo Dicionário de política:

A tese de que a virtude é transmissível pela via do sangue tem uma importância central na ideologia da Nobreza. É ela na verdade que tem como função justificar a transmissão por via hereditária dos privilégios nobiliários. Por isso, um indivíduo é tanto mais nobre quanto mais antiga for a Nobreza da família a que pertence, por ser maior o patrimônio de virtude que ele herda.

(BOBBIO; MATTEUCCI; PASQUINO, v. II, p. 828) 
Os limites históricos da Aristocracia (entenda-se a nobreza associada ao monarca absoluto) como classe dominante também são lembrados no mesmo verbete:

Quando o Ancien Régime for tomado de assalto pelas novas classes em ascensão, o monarca voltará a sentir-se e a comportar-se como o primeiro gentilhomem do reino e na queda final poder monárquico e poder nobiliário serão devorados juntamente. // Após a Revolução Francesa é afirmado o princípio da igualdade de todos os cidadãos perante a lei e as câmaras altas dos Estados reservadas na maior parte das vezes à Nobreza perdem gradualmente todo o poder político real. (BOBBIO; MATTEUCCI; PASQUINO, v. II, p. 832)

O fim do Ancien Régime, que acontece na França em finais do século XVIII, em Portugal começa quase três décadas depois e só vai se consolidar perto da metade do século XIX, com a derrota definitiva do absolutismo, e vai afetar diretamente um dos personagens de que trataremos. Mas o que importa dizer ainda aqui nesta introdução é que a concepção ideológica de Nobreza parece ter, no indivíduo que se acreditava pertencente a ela, perdurado para além da perda do poder político, e dos privilégios que essa concepção ideológica justificava. Ou seja, a ideologia sobreviveu após o desaparecimento da sociedade que lhe dava sentido material e político, permaneceu apesar da perda de quase qualquer outro sentido que pudesse ter, com exceção, talvez daquele capaz de alimentar a vaidade, a autoestima, o autoengano.

\section{II - Dois autores muito distantes no tempo e no espaço}

Uma das narrativas de que nos ocuparemos aqui foi escrita pelo português Camilo Castelo Branco (1825-1890) e publicada originalmente em 1867, na coletânea Cousas leves e pesadas. Tem por título: "Um parente de cincoenta e três monarcas". A outra foi escrita pelo angolano Manuel Rui (1941-) e publicada em 1973, no volume Regresso adiado. É o conto que abre o livro e chama-se "Mulato de sangue azul". Um autor português do século XIX, um autor angolano da segunda metade do século XX, narrativas distanciadas mais de um século, que poderão ter estes dois textos em comum?

Os títulos das duas narrativas já dão uma pista do contato, que é principalmente temático, entre elas. Os personagens principais desses dois contos acreditam convictamente em ideias como fidalguia, linhagem e nobreza hereditária. E não se trata apenas de acreditar, mas de encarnar essas ideias em suas próprias pessoas, pautar a vida e viver em acordo com elas. E também em desacordo com o entorno social que não mais reconhece a justeza delas. 
Em Camilo, o personagem Antonio Manoel tem apenas sua memória evocada e sua trajetória sumariamente reconstruída a partir de um documento por ele deixado e de testemunhos dos que o conheceram. Nenhum episódio de sua vida é encenado diante dos leitores. O tom da narrativa parece oscilar entre a zombaria, a piedade e a quase incontível perplexidade diante da vida miserável que levou o filho de tão ilustre linhagem, "descendente de todos os Reis de Portugal, da Hespanha, da França, e de todas as mais Nobres Famílias deste Reino" (BRANCO, p. 187).

Já Manuel Rui, valendo-se de um narrador em terceira pessoa, reconstrói dramática e comicamente momentos importantes, cenas da trajetória do personagem, para traçar o perfil do seu mulato de sangue azul, Luís Alvim, filho de Luís de Sampaio da Costa Alvim. O autor parece esticar, tensionar até o absurdo a sobrevivência da ideia da nobreza hereditária, entranhada num mestiço angolano por toda vida decidido a "afirmar a linhagem que o pai trouxera de Bragança" (RUI, p. 26).

\section{III - Aspirações e pretensões e presunções}

No conto oitocentista um narrador-personagem que atende pelo nome de Camilo (figura muito encontradiça ao longo da extensa obra ficcional do autor), estando "infeccionado do virus bibliomano" ${ }^{2}$, conta-nos suas andanças pela cidade de Braga em busca de livros e manuscritos antigos, procurando neles os

\footnotetext{
honrados portuguezes de ha trezentos annos, que, envoltos nas suas alvacentas mortalhas de pergaminho, nos apparecem como espectros accusadores, e particularmente a mim, increpando-me de uns folhetos e librecos com que me ando, ha vinte annos, apestando a lingua e as almas.

(BRANCO, p. 181, vale para a citação anterior.)
}

Ao falar nesses "honrados portuguezes de ha trezentos annos" o narrador está introduzindo o tema do conto. Entre as compras feitas na ocasião incluiu-se um manuscrito intitulado “Apparato genealogico de Antonio Manoel d'Antas de Vasconcellos e Castro", obra que descrevia a linhagem do seu autor e em que também se viam "muitos brazões, intercalados nas páginas manuscriptas" (BRANCO, p. 184, vale para a citação anterior). Posteriormente o narrador nos dará um sumário do conteúdo da obra, afiançando que ele se sustenta em fontes e autoridades reconhecidas "de tal tomo que não deixam gretar a veracidade da prosapia". Informa o narrador

\footnotetext{
2 Nesta, como nas outras citações de Camilo, mantivemos a ortografia da edição com que trabalhamos, que é de 1936.
} 
(aproveitando em seguida para cutucar com seu sarcasmo habitual as pretensões dos herdeiros de outras linhagens, menos documentadas que a de Antonio Manoel):

Rebenta a fronde dos Antas no tronco real do rei godo Amalarico, aos 515 annos de Christo. Vê-se que a familia é antiga; mas ha ai fidalgas vaidades que vão mais longe. Ha sujeitos que iriam procurar as ruinas do seu solar no paraiso terreal, se não receassem encontrar o seu penultimo avô na pessoa de Caim. Honrado receio! (BRANCO, p. 185 , vale para a citação anterior.)

Assim o próprio Antonio Manoel faz um sumário da sua linhagem:

E acrescenta epilogando: "Por tanto, (trasladamos grammatical e ortographicamente, por nos parecer um desacato qualquer alteração) por tanto bem á haver neste livro e no sangue do Autor, alem d'Outros muito mais, que se não escreverão, os Titulos seguintes: Reis 53 Infantes 14 - Duques 5 - Condes 38 - Alcaides 39 - Somão Tittolos 149, Alem de Marquezes, Viscondes, Ricos-Homens, Condessas, Viscondessas, Rainhas, Infantas, Generaes, Arcebispos, Bispos, Sanctos, Meirinhos-mores, etc."

(BRANCO, p. 186-187)

Interessante notar como os santos são alinhados, sem distinção em nobreza, aos generais, arcebispos, bispos e aos meirinhos-mores. Uma hipótese que nos ocorre, para este alinhamento, é estarem todas essas figuras associadas a alguma espécie de atividade de controle social, incluído o repressivo.

Já Luís Alvim, no conto de Manuel Rui, se não tem um livro de linhagem para mostrar, mostra, logo na cena de abertura, na estação ferroviária, visto que está mudando de Benguela para o Chinguar, no planalto, mostra, dizíamos, alguns objetos que deveriam ser distintivos da sua condição de superioridade, marcas da sua nobreza hereditária: "a bengala encastoada que fora de seu pai"; "fato preto"; "sapatos de verniz"; "relógio de bolso preso por corrente de ouro". E como sua condição de mestiço na sociedade colonial em nada contribuía para sublinhar a elevação a que ele aspirava na dita sociedade, era preciso passar o mais que pudesse por branco.

Seu cabelo de mulato empasta-se num disfarce por camadas de brilhantina que alisam as repas maiores em pequenas ondas. Não tem cabelo que voa, mas de longe, com a clareza da pele e a carapinha escondida, tem sua maneira de cabrito, ao menos. De perto, percebe-se o engano: carapinha sem liberdade e brilhantina escorrendo pelo risco, do lado esquerdo da cabeça.

(RUI, p. 25, vale para as citações anteriores não identificadas.) 
Numa sociedade dividida entre colonos (colonizadores) e colonizados, em que a cor da pele servia como comprovação evidente e incontornável da superioridade ou da inferioridade social, o absurdo começou com as pretensões do pai de Luís Alvim. "Luís de Sampaio Costa Alvim, de seu nome completo como consta nos cardápios, sempre se julgara um homem superior entre os outros colonos. Era nobre de sangue.” (RUI, p. 26) Não satisfeito em se considerar superior aos colonizados, negros e mestiços, ainda se julgava superior aos colonizadores e colonos, ou seja, a todos os brancos. Mas o absurdo se potencializa em seu filho, um mestiço que, no limite, também se julgava superior a negros e mestiços ("Alvim fugia de negros e mulatos, e muamba, prato dos domingos benguelenses, só comia às escondidas", RUI, p. 29) e, pelo menos secretamente, a todos os brancos que não tinham sangue azul, como ele. Eis aqui o juízo que o personagem fazia de si mesmo:

Luís Alvim nunca se considerou um mulato benguelista de bravura, dançarino, brigão ou de pontapé na bola. Foi mesmo de evitar qualquer requebro no andar. Filho mais velho do colono de Bragança, teve ensejo de figurar nos registos com o nome de Alvim e de fazer exame do segundo grau. (...) // Em Benguela, Alvim caprichou, sempre, em pronunciar um português correcto. Em acenar com a mão esquerda, atirando seu anel de brasão às vistas, na resposta aos "olá sôr Alvim”. (RUI, p. 28-29)

O anel de brasão é mais um dos distintivos materiais de sua presumida condição de superioridade e de nobreza.

\section{IV - A dureza da vida em choque com o sonho}

Logo após nos dar notícia do conteúdo do Apparato genealogico de Antonio Manoel, o narrador camiliano apresenta o outro lado da moeda. "Saibamos agora quem, real e positivamente, era este primo de cincoenta e tres monarchas." (BRANCO, p. 187, grifo nosso.)

O leitor passa a ser informado que Antonio Manoel nasceu em 1794, portanto ainda no século XVIII e em plena vigência do Ancien Régime em Portugal. Mesmo nesse regime político favorável à nobreza, a sua condição de linhagem em nada lhe valeu, visto que ele nasceu pobre, pois seu pai já era pobre, consequência "de seu avô, grande perdulário, ter desvinculado e esbanjado os paços d'Antas e suas pertenças" (BRANCO, p. 187). Mas em 1826, quando Antonio Manoel vai a Lisboa, à Corte, "procurar sua vida", os ventos voltavam a soprar favoráveis ao absolutismo, com o 
retorno de D. Miguel, até então no exílio, a Portugal. Nesse ano Antonio Manoel é agraciado com o hábito de Cristo e, mais importante, um emprego público que lhe permitirá manter-se. Mas por questões de saúde volta à província, arrendando ou vendendo seu emprego em Lisboa. Casou-se “com D. Francisca Luiza Pinto Bacellar de Gondim, filha de Domingos Pinto, governador que foi de Monção, dama por igual illustre e pobre." Como se pode perceber, Antonio Manoel continuava dando mais valor à linhagem, à nobreza e ao sangue do que às necessidades materiais. A dureza da vida que levava está bem esboçada neste comentário feito pelo narrador:

Como qualquer mortal que não tivesse cincoenta e tres monarchas na sua familia, Antonio Manoel atamancava mal sua vida, era a miudo palpado pela mão adunca da miseria, e, para nenhuma entreaberta de esperança lhe sorrir, os filhos nasciam-lhe aos pares.

(BRANCO, p. 188, vale para as citações anteriores, não identificadas.)

Também a situação política contribui para tornar ainda mais dura a vida de Antonio Manoel. Lembremos que em 1834 deu-se a queda definitiva de D. Miguel, com a vitória dos liberais em Évora-Monte e D. Pedro, o que tinha sido Imperador do Brasil, assumindo o trono português:

Apertado pelas privações, que a mudança de governo aggravára, Antonio Manoel lançou mão dos recursos litterarios de que se julgou ainda favorecido. Fez-se nomear mestre regio de primeiras lettras em Braga, ahi por 1835. // N'este tempo e nos annos subsequentes até 1838 , o mestre regio, nas poucas horas feriadas do rapazio, escreveu o seu "Apparato genealogico" sabe Deus com que amarguras, curando assim de rebater as humiliações e vingar-se dos affrontamentos de sua ruim sorte.

Depois disso os informadores do narrador dão conta da enfermidade da esposa de Antonio Manoel, que em consequência dela ficou paralítica, da doença que em seguida o acometeu e da qual veio a morrer sozinho, num catre de caridade dum hospital. A mulher também logo o seguiu "pela curta ladeira das dôres, das saudades e da fome" (BRANCO, p. 189, vale para a citação anterior, não identificada) e ficaram um filho e duas filhas. Do filho nada foi possível apurar e as filhas, soube o narrador, vivem de esmolas. Este era o destino das descendentes de uma tão longa e depurada linhagem, no momento em que uma nova nobreza, desprovida de ancestrais ilustres, abria caminho ascendente no novo regime, podendo agora comprar suas posições e títulos a peso de ouro. 
Ressalvado o fato de que Luís Alvim, em sua condição de empregado no aparelho burocrático da administração colonial, viveu materialmente melhor que o sofrido Antonio Manoel, atamancou melhor sua vida, aproveitando o saboroso dizer do narrador camiliano, também a ele, como a Antonio Manoel, a sociedade não deu nunca o reconhecimento de que eles se achavam merecedores. Era esse o motivo dele deixar Benguela, sua cidade natal.

Para Luís Alvim, Benguela é uma terra ingrata, esquecida de seus maiores. Por isso, esperar esse comboio faz sofrer. Aguentou trinta e cinco anos na cidade de S. Filipe. Trinta e cinco anos de luta e incompreensão. De insistência. Na tentativa de afirmar a linhagem que o pai trouxera de Bragança. (RUI, p. 26)

Mas para "afirmar a linhagem que o pai trouxera de Bragança" era preciso negar a outra metade da sua linhagem, o que de novo o punha em conflito com a sociedade de que era originário: "esqueceu cedo quatro irmãos mulatos benguelistas de pureza, e três irmãs prostitutas" (RUI, p. 28). Além dos irmãos e irmãs havia "a incómoda recordação da mãe" (RUI, p. 29), que "regressou à sanzala (...), sobrevivendo com o auxílio das filhas que vendiam, barato, o corpo já cansado na cidade" (RUI, p. 30).

Sua esperança, em seu novo destino, era uma só, a mesma, aliás, não alcançada em trinta e cinco anos de vida em Benguela.

Mulato Alvim conseguira transferir-se nas funções de escriturário administrativo, com a esperança de encontrar, à sombra da monotonia da vila, ambiente propício às plumas, ao prosaísmo da linhagem nobiliárquica. // Começou por pavonear-se dentro da clássica fatiota preta que vestia à tarde, quando largava da administração. (RUI, p. 30)

E também ali, no Chinguar, a dureza da vida depressa atropelou aquela invencível esperança. A crua impiedade da linguagem parece mimetizar a violência do choque. Enquanto Luís Alvim pretendia-se superior (por hereditariedade) aos dois grupos, brancos e negros concordavam, e era uma das poucas coisas em que concordavam, em igualmente desprezar os mestiços. "Mas depressa se apercebeu de uma verdade: no interior há poucos mulatos e duas manias. Os brancos adiantam que mulato é filho de uma nota de vinte paus; os pretos, sempre que um mulato arreganha, cospem que mulato não tem terra." (RUI, p. 30-31)

Depois de não conseguir ser admitido no convívio dos brancos, Alvim acaba por fazer parte de um grupo de mestiços em que também havia um negro assimilado, e nesse grupo ele conheceu o camionista (ou caminhoneiro) Xavier. Após um tempo de 
convivência, Alvim atreveu-se a confidenciar sua nobreza de sangue, sua categoria de mulato de sangue azul, ao novo amigo. E o que ouve dele, depois de toda a história, acaba por lhe provocar um incômodo choque de realidade que ele, após um intervalo para se acalmar, é claro, rejeita.

- Desculpe, mas essa história de sangue azul não me entra! Essa gente tem cabelo loiro, olhos azuis. Você nem sequer foi a Lisboa! Não o quiseram para soldado, no seu tempo, mulato não entrava na tropa! Pópilas! Já se viu mulato assim? Você é mulato como outro qualquer. Sua mãe é preta. Ainda bengala os sobas também usam e... // — Encastoada? // - Em quê não sei... em pau. Mas estava a dizer que sua mãe é preta e você é mulato para todos os efeitos. Não é muito escuro mas seu cabelo tem alisamento de... desculpe... brilhantina. Não pode ter a mania de branco importante. Oiça, sou de Pereira de Eça, lá no fim do Sul. Muitas vezes andei com meu pai em viagens de camioneta para o Sudoeste Africano. Quando chegávamos à fronteira, o velho dizia: "Vá, rapaz, salta da cabina." E eu ia amochar na carroçaria, junto com o ajudante preto que ria dessa coisa. Nunca me esquece. Você lá no Sudoeste, com todo o sangue azul, não risca, pá! É mulato, não escapa. Não pense nisso! // Alvim ficou petrificado com as achegas do amigo e, nessa noite, levantou-se quatro vezes para enganar a insônia com cigarros. Xavier era cafrealizado! Ele, funcionário da administração, com dois louvores, conhecedor de toda a linguagem requerimenteira, alguma vez aceitava subir para trás, com o ajudante preto, só por causa da fronteira? Zarpou um manguito! Mulato estúpido, Xavier! Contemplou o brasão, observou o relógio nas três da manhã, e deu passos com a bengala. Qual quê! O sono, nada. A ideia do mulato vulgar massacrava-o. De madrugada até a hora de seguir para a repartição, a cama foi um pesadelo sem fim com vissonde a comer-lhe os dedos e o salalé a penetrar na bengala.

(RUI, p. 35-36)

Note-se como o motivo do cabelo volta a ser mencionado, como Alvim necessita dos seus distintivos e símbolos materiais de nobreza para acalmar o coração abalado pelo que ouviu, como aplica em Xavier a mesma classe de preconceito com que brancos segregam brancos que adotam os costumes dos negros (“cafrealizado!”) e como, em seu pesadelo, ele vê atacados os seus símbolos de nobreza, os dedos, por extensão, o anel, e o cupim dando na bengala.

Outro choque do sonho com o perpétuo caráter de estraga-prazeres da realidade dá-se quando Luís Alvim, informado por Xavier que chegara à vila um médico de sobrenome Alvim, quis levar seus cumprimentos ao presumível parente.

Luís Alvim andou a semana inteira perturbado a inventar o palavrório com que se havia de apresentar ao médico, seu indiscutível parente, pois, como afirmava o velho Luís de Sampaio Costa Alvim, em todo o Portugal, senão no mundo, só existia uma família possuidora de nome 
tão raro. Uma família que se distribuía por dois ramos, os de Bragança e os de Évora. Não havia razões para dúvidas. O médico era seu parente, e Luís Alvim devia apresentar-se quanto antes, não fosse o doutor levar a mal. (RUI, p. 36-37)

E eis o que lhe disse o médico quando ele devidamente enfatiotado a rigor, apareceu para a visita protocolar e declarou o pretenso parentesco:

- Caro amigo, agradeço imenso a sua gentileza mas não pertenço a nenhuma dessas famílias ou ramos. Sou de Mortágua... // - Onde fica? - atalhou Luís Alvim em desespero de causa. // - Muito longe, muito longe de Évora ou de Bragança. Mas como lhe ia dizendo, para além disso, sou de família humilde, meu pai é lavrador. Vim para Angola com o fito de conseguir um pé-de-meia que me permita regressar à metrópole para depois tirar uma especialidade no estrangeiro. - E, coçando a cabeça, prosseguiu: - Não vejo qualquer ligação com os... (RUI, p. 39-40)

Aquele encontro foi causa de muito sofrimento. E em seu raivoso desabafo solitário Luís Alvim explicita o que já o leitor suspeitava: assim como seu pai, ele está tão descosido da realidade que também se julga superior a todos na colônia, e evidencia seu preconceito aristocrático contra o trabalho ("filho de um lavrador!"), esquecendo que ele próprio era um funcionário administrativo.

Chorou de mágoa essa noite e só desejou não mais encontrar o amigo Xavier. Bem vistas as coisas, nunca devia ter dado confiança àquele mulato sanzaleiro e a seus comparsas. Ao fim e ao cabo, era filho de Luís de Sampaio Costa Alvim. Ninguém lho podia negar. Estava no registo! Era mais que o médico, até! Esse doutor de merda, teso, filho de um lavrador! Se calhar caíra numa ratoeira armada por Xavier, que o aconselhara na chacota, para gozar depois o resultado em gargalhada geral no bar "Europa". E essa! Mulato ordinário! // Triste, adormeceu consolado na certeza: era de sangue azul! (RUI, p. 40)

Falávamos, entre outras coisas, no autoengano em que vivem estes personagens.

Eis aí a demonstração literal de como ele pode servir de consolo.

\section{V - A questão política num e noutro século}

Acreditamos ter demonstrado satisfatoriamente a dualidade entre vida e sonho, mundo material e mundo ideal, trivialidade cotidiana preterida em favor do imaginário na trajetória dos dois personagens examinados. A preponderância do imaginário sobre a realidade concreta ainda permite a discussão de um último ponto: como essa postura parece propiciar uma espécie de cegueira irremovível, incurável, dos personagens diante das questões políticas. Tais princípios ideológicos e crenças pessoais parecem conduzir 
à evasão da realidade e a uma forma bem particular de alienação social, impedindo a percepção crítica do que acontece à volta deles e levando, pelo menos num dos casos, o personagem à destruição.

Considerando a narrativa de Camilo Castelo Branco, isso fica evidente, com direito a comentário do narrador, no tratamento que Antonio Manoel dá ao seu também parente, mas adversário político, D. Pedro, irmão de D. Miguel.

Que Antonio Manoel era homem de bem o está dizendo este manuscripto. Realista devia elle de ser entranhadamente, por legado de avós, e por interesses que a mudança de instituições lhe desbalisou. Pois vejam a prudencia e circumspecção com que elle falla do Snr. D. Pedro de Bragança: "D. Pedro imperador do Brazil, veio com tropas estrangeiras, e com sua filha D. Maria da Gloria Princeza do Grã-Pará, intitulou-se Rei de Portugal, ataca D. Miguel que estava Rei pela Nação, e vencendo-o com o apoio estrangeiro, lançou o irmão fóra." E mais nada! Vê-se que Antonio Manoel não quis offender um parente, embora rei illegitimo, no seu modo de vêr. (BRANCO, p. 190)

Outro índice do desamparo em que Antonio Manoel caiu ao fim da sua trajetória é a patética página final (BRANCO, p. 191-192) do seu "Apparato", em que de alguma forma também se faz presente o ridículo, transcrita na íntegra pelo narrador ("Veja o leitor commigo esta pagina; e se não chorar, ao menos soffreie o riso."). Nela o autor apela à divindade, único poder que ele crê ainda capaz de ouvi-lo e fazer alguma coisa em sua defesa. Mas também a divindade, pensa o narrador, nada quererá fazer por ele e por seus apelos, deixando de corroborar a sentença contra "meus herdeiros legitimos, se por acaso emprestarem, venderem, trocarem, perderem, ou derem este livro", e também contra "todas as mais pessoas que o tirarem ou comprarem, ou furtarem, ou aceitarem este livro" (BRANCO, p. 191, vale para as citações anteriores, não identificadas), visto que o crime para o qual o parente de cinquenta e três monarcas pede o castigo da excomunhão eterna possui fortes atenuantes, entre elas a necessidade incontornável de matar a fome.

Já Luís Alvim, ainda abalado pela frustração da sua visita ao médico e nãoparente Alvim, com medo da zombaria que, acreditava ele, lhe fora preparada, sofre, no dia seguinte, para seu deleite e prazer pessoal, uma completa reversão de expectativas. Chamado ao gabinete do administrador, à espera de uma descompostura por se atrever a perturbar um branco, viu-se travando o seguinte diálogo com a autoridade e viu a sua vida mudada, seu talento, sua virtude, sua nobreza, enfim reconhecidos: 
- Alvim. Tenho admirado as suas qualidades de funcionário, cumpridor, leal e atento ao serviço. E mais, a sua maneira de ser, a sua finura no trato. Se não é indiscrição, onde é que foi educado? // - Em casa de meu pai, Luís de Sampaio Costa Alvim, que foi funcionário administrativo em Benguela, descendente de uma das mais distintas famílias portuguesas. // - Nota-se. Nota-se. Pois bem, você não está no lugar que merece e vou-lhe propor uma oportunidade única de evidenciar toda a sua categoria. // Luís Alvim estremeceu, meio contente meio medroso, no ínterim da expectativa. Que raio era aquilo? A brincadeira continuava ou quê? $\mathrm{O}$ administrador esclareceu: // - Precisamos de uma pessoa como você, culta e educada. Que vá pelo Norte fora contar a essa gente a verdade. Tenho uma circular de Luanda onde indirectamente lhe formulam o convite. Incluindo ajudas de custo passa a ganhar o dobro. Fica com uma carrinha à disposição, com aparelhagem sonora. A sua voz será ouvida e respeitada em todo o lado, por gente de todas as cores, senhor Alvim.

(RUI, p. 41-42)

O administrador nem fazia ideia de como Luís Alvim estava distante da cultura do colonizado e próximo da cultura do colonizador:

— Preciso é de um intérprete. // - Julguei que você... // - Saiba o senhor administrador que só falo português. // - Bem, isso é o menos. Arranja-se o intérprete e desde já o felicito. // E foi assim que o mulato de sangue azul, desconhecido até então, passou a botar discurso ambulante, boquiabrindo povoações, sanzalas e quimbos. Explicando, sempre com eloquência, uma maneira do como e porquê dos factos. Dizendo da gajada que andava, com armas espera-pouco, incomodando populações de bem que transitavam nas estradas ou viviam no Norte. // Luís Alvim. // Locutor da voz da verdade. // Mulato de sangue azul. (RUI, p. 42)

É este diálogo e esta circunstância que permitem ao leitor situar historicamente o final da trajetória de Luís Alvim. Estamos em 1961, já aconteceram os ataques da União dos Povos de Angola no Norte do território, contra os fazendeiros brancos e todos, mestiços ou negros, que a eles estivessem ligados. É o início da guerra de libertação. Salazar providencia o envio de tropas para Angola, em força! Se a situação não é mais explicitada no texto, talvez seja porque em 1973, data da primeira publicação do conto, embora Salazar já estivesse morto, a ditadura portuguesa ainda sobrevivia (nas últimas) e era preciso não provocar a ainda atuante censura com referências demasiadamente explícitas.

O resultado da tarefa que a administração colonial dera a Luís Alvim não podia ser outro. Xavier, na volta de uma de suas viagens de caminhão para o Norte, foi quem trouxe a notícia porque o tinha visto. E um detalhe da aparência dele marcou vivamente Xavier. 
Luís Alvim morrera. // Fora encontrado com um balázio na cabeça, à beira da estrada. // Viu Alvim, morto e vestido com um camuflado. Xavier contava sem se impressionar. Só um pormenor o arrepiava. Dentro do caixão improvisado, o cabelo de Alvim não estava como dantes. Quando acharam o corpo, dizem, o mulato estava nu, com a cabeça manchada de sangue. Vestiram-lhe um camuflado e lavaramlhe a cabeça, penteando o cabelo para trás, desbrilhantinado. Amarrafaram a cara de Alvim. Aquele não era o seu amigo de risco ao lado e cabelo de onda miúda. Pentearam mal o cabelo de Alvim. // De como e porquê fogacharam esse mulato, Xavier não contou nem sabe. Só o viu morto, sem risco e de camuflado, dentro das tábuas de caixotes de sabão. // Mulato de sangue azul que morrera no seu posto. $\mathrm{Na}$ tarefa de conciliar o inconciliável. De vazar o sangue da mãe, negra de Benguela, sabedora de histórias carnais antigas do tempo em que o povo sem conta saía nos barcos para o mundo. De sobressair o sangue de seu pai da indelével mistura com o sangue que a mãe herdara de gente escrava. // Ia longe Luís Alvim. // (...) // Do coração, ninguém teve pena dele. Nem brancos, nem mulatos, nem pretos.

(RUI, p. 44-45)

Assim como a "Escuminhão" redigida por Antonio Manoel para fecho do seu Apparato genealogico pode ser vista como uma espécie de epitáfio para o personagem, Luís Alvim também teve a sua nênia, composta pelo camionista e tocada ao som da sua viola:

Só Xavier, entre uma cerveja e outra, penaliza o penteado do morto e, num tanger dolente, pisa com os dedos calejados da mão esquerda as cordas da viola, pousa o cigarro na ponta da mesa, engole um trago e timbra um cantar que ninguém acompanha, / não foi sina não foi morte / que matou Luís Alvim... // - Aquele gajo não andava bom dos miolos! Como é que mulato pode ser de sangue azul? // E acrescenta, / mulato de sangue azul / tinha de ter esse fim... (RUI, p. 44)

E ao som da viola de Xavier termina esta rápida leitura dos perfis de dois personagens em que a sobrevivência de lastros ideológicos arcaicos, contendo elementos da nobreza hereditária, também dita aristocrática, impediu que eles fossem capazes de alcançar uma compreensão dos verdadeiros aspectos da realidade à volta deles, ambos preferindo viver na fantasia.

\section{REFERÊNCIAS BIBLIOGRÁFICAS:}

BOBBIO, Norberto; MATTEUCCI, Nicola; PASQUINO, Gianfranco. Dicionário de política. Vol. I. 8a . ed. Trad. Carmen C. Varrialle, Gaetano Lo Mônaco, João Ferreira, Luís Guerreiro Pinto Cacais e Renzo Dini. Brasília: Editora UnB, s. d. 
BOBBIO, Norberto; MATTEUCCI, Nicola; PASQUINO, Gianfranco. Dicionário de política. Vol. II. $8^{\text {a }}$. ed. Trad. Carmen C. Varrialle, Gaetano Lo Mônaco, João Ferreira, Luís Guerreiro Pinto Cacais e Renzo Dini. Brasília: Editora UnB, s. d.

BRANCO, Camilo Castelo. "Um parente de cincoenta e tres monarchas" In Cousas leves e pesadas. $3^{\mathrm{a}}$. ed. Lisboa: Parceria Antonio Maria Pereira, 1936, p. 179-192.

JAMESON, Fredric. $O$ inconsciente político: a narrativa como ato socialmente simbólico. Trad. Valter Lellis Siqueira. São Paulo: Ática, 1992.

RUI, Manuel. "Mulato de sangue azul” In Regresso adiado. 2a . ed. Lisboa: Edições 70, 1978, p. 23-44. 